Article

\title{
Does Evil Prevail? The "Bright" and "Dark" Sides of Personality as Predictors of Adaptive Performance
}

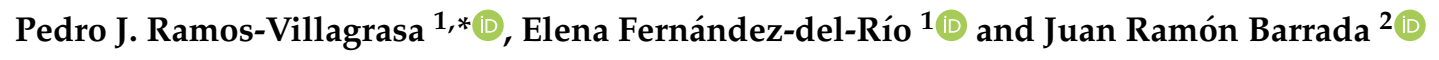 \\ 1 Faculty of Social Sciences and Labour, University of Zaragoza, Calle Violante de Hungría, 23, \\ 50009 Zaragoza, Spain; elenario@unizar.es \\ 2 Faculty of Humanities and Social Sciences, University of Zaragoza, Calle Ciudad Escolar, 44003 Teruel, \\ Spain; barrada@unizar.es \\ * Correspondence: pjramos@unizar.es; Tel.: +34-876-554-555
}

Received: 1 December 2019; Accepted: 7 January 2020; Published: 8 January 2020

\begin{abstract}
The turbulent context in which organizations operate today makes them search for adaptable workers. Previous studies have shown the predictive value of the "Big Five" personality traits on adaptive performance, but some authors suggest extending personality domain with the "dark" traits of personality, that is, Machiavellianism, narcissism, psychopathy (i.e., the "Dark Triad"), and sadism (which, along with the aforementioned traits, composes the "Dark Tetrad"). The present research investigates the incremental validity of the dark traits in the prediction of adaptive performance over the Big Five. The study follows a cross-sectional design with a convenience sample of 613 participants ( $46 \%$ women; mean age 38.78 years, $S D=14.05$; mean job experience $=16.93$ years, $S D=13.39$ ) from different organizations who fill in a questionnaire with the variables. Our results showed that the Dark Triad improved the predictive model with respect to the Big Five $\left(R^{2}=0.202, \Delta R^{2}=0.030\right.$, $p<0.001)$. The statistically significant predictors were neuroticism $(\beta=-0.127, p=0.010)$, openness to experience $(\beta=0.155, p<0.001)$, conscientiousness $(\beta=0.164, p=0.001)$, narcissism $(\beta=0.134$ $p<0.002)$, and psychopathy $(\beta=-0.137, p=0.005)$. The incorporation of sadism did not improve the Dark Triad model $\left(R^{2}=0.202, \Delta R^{2}=-0.001, p=0.541\right)$.
\end{abstract}

Keywords: job performance; adaptive performance; Big Five; dark personality traits; dark tetrad; narcissism; Machiavellianism; psychopathy; sadism

\section{Introduction}

Interest in how organizations contribute to sustainability has grown in the last few years. This contribution goes beyond the physical environment, considering also the extent to which organizational practices promote workers' well-being [1]. A key process that helps organizations to be sustainable is personnel selection [2], which consists of incorporation, through a fair and transparent process, of workers who best fit the job. To do this, is necessary for the selection instruments to demonstrate their relationship with performance. One of the current challenges in this respect is that most workers are employed in organizations characterized by change and unpredictability [3]. They must face the effects of the global economic crisis that began in 2008 and whose effects are still being felt $[4,5]$. This scenario leads to changes in their career (e.g., short-term contracts in different workplaces or even different organizations), in their duties (e.g., being a leader in one project but a follower in the next one), in their tasks (e.g., modification of work instructions according to new standards), and so on. How workers cope with these changes is fundamental to their well-being. Unsuccessful adaptation can lead to the loss of resources (e.g., organizational support, enjoyment of work [6]) and also to the increase of job insecurity [7]. At the same time, these negative consequences impact on the workers' health in terms of stress, burnout, negative emotions, etc. [6-9]. Therefore, being able to identify the most adaptable workers is a way to pursue organizational goals and at the same time to prevent 
the emergence of psychosocial risks in the workplace. This lead to study the prediction of adaptive behaviors, also called adaptive performance [10].

Personality, especially conceptualized as the "Big Five" personality traits (i.e., neuroticism, extraversion, openness to experience, agreeableness, and conscientiousness), is one of the main personal variables related to successful adaptation at work $[8,10]$ and to job performance [11]. However, at the same time that evidence in favor of the Big Five continues to grow, researchers are considering that it is necessary to extend the "bright" Big Five traits with other subclinical traits considered "dark": narcissism, Machiavellianism, and psychopathy [12-15]. Although all of them have common features like callousness, they are different traits [16]. The first trait, narcissism, is characterized by a dysfunctional need for excessive attention, an inflated sense of entitlement, requiring excessive admiration, lack of empathy, over-confidence, and a high propensity for engaging in exploitive behaviors [14]. The second trait, Machiavellianism, describes individuals characterized by a high ability to manipulate other people, lack of empathy, lower levels of affect, focus on achieving their own goals at the expense of others, and showing questionable ethics [14]. The third trait, psychopathy, is characterized by low empathy and guilt, lack of remorse, superficial charm, egocentricity, impulsivity, sensation-seeking, and manipulativeness [17]. Recently, Paulhus [18] suggested that everyday sadism (i.e., enjoyment of cruelty [19]) should also be added to the dark personality, composing the "Dark Tetrad". Sadism shares characteristics with the remaining dark personality traits, such as callousness and readiness for emotional involvement, but empirical evidence suggests that this trait is different from the remaining traits and that it cannot be reduced to them [20]. Thus, Buckels and colleagues [19] have found that sadism emerged as an independent predictor of behavior reflecting an appetite for cruelty, including the performance of boring tasks for the opportunity to behave aggressively [21]. In fact, compared to the other three dark traits, sadistic individuals do not need an external incitement to show negative behaviors (i.e., aggression) because cruelty in itself is directly reinforcing.

Recently, two studies have shown that some of the dark traits are related to adaptation at work [22,23]. Continuing this line of research, the present paper aims to investigate the incremental value of the Dark Tetrad over the Big Five in the prediction of adaptive performance.

\subsection{Adaptive Performance}

It is well-recognized that job performance is a multidimensional construct with different but related kinds of performance [24]: (1) task performance, "behaviors that contribute to the production of a good or the provision of a service" (p. 67); (2) contextual performance, "behavior that contributes to the goals of the organization by contributing to its social and psychological environment" (pp. 67-68); and (3) counterproductive work behaviors, "voluntary behavior that harms the well-being of the organization" (p. 69). However, currently the performance domain is expanding with other dimensions like safety performance [25], creative and innovative performance [26], or adaptive performance [27]. The present paper is focused on the last one.

Adaptive performance is a construct used to describe adaptation as action, referring to the behaviors displayed by workers to change according to job demands [3]. Although adaptive performance may look like task performance, it implies performing the same activity "to a greater degree, with greater intensity, or in a substantially different way" [28]. In that sense, a longitudinal study developed by Griffin, Parker, and Mason [29] found support for the distinction between proficient and emergent behaviors, each one involving different antecedents. Proficient behaviors contribute to organizational results when work requirements can be anticipated (i.e., task performance), whilst emergent behaviors are change-oriented (i.e., adaptive performance).

Pulakos and colleagues [27] proposed a taxonomy of eight adaptive behaviors, although their use depends on the specific adaptive situation. These behaviors are: (1) solving problems creatively; (2) dealing with uncertain or unpredictable work situations; (3) learning new tasks, technologies, and procedures; (4) demonstrating interpersonal adaptability; (5) demonstrating cultural adaptability; (6) demonstrating physical-oriented adaptability; (7) handling work stress; and (8) handling emergencies and crises. 
This taxonomy serves as a framework to classify the wide array of adaptive behaviors that can be found in the work setting. Despite the fact that it comprises different behaviors, the meta-analytic research performed by Huang and colleagues [8] has provided evidence of the unidimensionality of adaptive performance, unlike other dimensions such as counterproductive work behavior, which has sub-dimensions [30].

As occurs with the remaining performance domains, the identification of adaptive performance antecedents may help human resource management practices, like developing an adaptive workforce [31]. According to the review by Jundt et al. [10], adaptive performance has proximal and distal predictors. The proximal predictors, which are specifically related to the adaptive episode, include two different sets of antecedents: (1) motivation and self-regulation, and (2) cognitive processes and behavioral strategies. On another hand, the distal predictors are personal and job-related antecedents that are relatively stable over time and across individuals, and which comprise three different categories: (1) individual differences; (2) training techniques and learning strategies; and (3) job, task, and contextual factors.

Of all the aforementioned predictors, the study of individual differences seems especially interesting. Identifying the adaptive performance predictors that vary among individuals will contribute to personnel decision making. So far, differences in cognitive ability, personality, goal orientation, self-efficacy, self-leadership, and some demographic factors (sex, education, employability, job experience) have been shown to be predictors of adaptive performance $[9,10,32,33]$. The challenge for researchers now lies in deepening these relationships by identifying specific variables (e.g., personality traits), in which adaptive situations they operate, and how they promote adaptation [10]. In the present study, we shall focus on personality and the recent developments suggesting that dark traits may extend the contribution of personality to explain adaptation.

\subsection{Personality and Performance}

Personality is one of the classical predictors of job performance. Most research on bright personality at work has been developed following the Big Five model. Big Five traits are among the most important constructs related to job performance [11], although the relevance of each trait varies depending on the dimension of performance under study. Regarding adaptive performance, Huang et al. [8] performed a meta-analytic study of the role of personality in the prediction of adaptive performance. Personality was measured with the Hogan Personality Inventory, which maps strongly onto the Big Five [8]. They analyzed 71 independent samples $(N=7535)$ and concluded that neuroticism (measured as emotional stability, $r=0.12, p \leq 0.05$ ), ambition (which maps extraversion, $r=-0.11, p \leq 0.05$ ), inquisitiveness (which maps openness, $r=0.03, p \leq 0.05$ ), and learning approach (which also maps openness, $r=0.06, p \leq 0.05$ ) were all positively related to adaptive performance. In addition to this meta-analysis, Jundt et al. (2015) performed a literature review in which they concluded that empirical evidence indicated that conscientiousness was positively related to adaptive performance. Recently, Christian and colleagues [34] performed a meta-analytic investigation with adaptive performance of teams as criterion. They found statistically significant mean corrected correlations between adaptive performance and two Big Five traits: emotional stability $(r=0.14$, $p \leq 0.05)$ and openness $(r=0.08, p \leq 0.05)$.

As mentioned, the other side is dark personality. Since Paulhus and Williams proposed the Dark Triad [14], studies have been developed to investigate its relationship with the Big Five. Results have shown that the dark traits are independent dimensions of personality and their relationship with the Big Five is scarce, except for agreeableness [35,36]. However, the debate continues regarding the HEXACO model (i.e., the Big Five and Honesty/Humility) and dark personality. Some authors argue that Honesty/Humility completely overlaps dark personality [37,38], but there is also evidence about their independence $[21,36]$. In any event, research has established that dark personality is related to job performance. For example, a recent meta-analysis [39] has shown that, once the correlations have been corrected for attenuation, Machiavellianism and psychopathy had small but significant negative relationships with task performance $(r=-0.06, p \leq 0.01$ for Machiavellianism and $r=-0.08, p \leq 0.01$ for 
psychopathy), and that all dimensions of the dark triad were positively related to counterproductive behaviors $(r=0.20, p \leq 0.01$ for Machiavellianism, $r=0.35, p \leq 0.01$ for narcissism, and $r=0.06, p \leq 0.01$ for psychopathy). On sadism, the last trait to be incorporated into the construct, there is only one study analyzing its predictive capacity of performance. This study, conducted by Fernández del Río and colleagues [21] found that, once the remaining traits were controlled for (i.e., Big Five, Honesty/Humility, and the Dark Triad), sadism contributed significantly to explain task performance, with which it was negatively related, and counterproductive work behaviors, with which it was positively related.

Although dark personality contributes to the classical dimensions of job performance, the adaptive functioning of some of these personality traits at specific levels or in limited contexts should be taken into account [40]. In that sense, two primary studies have shown that dark personality also has a positive relationship with adaptiveness. The first one shows that, although psychopathy is not related to adaptive performance, when the worker had political skills (e.g., social astuteness, networking ability), it contributed positively to adaptive performance, $\beta=0.20, p \leq 0.05$ [22]. The other study, performed by Smith and Webster [23], showed that narcissists were more likely to take chances, which in turn allowed them to be more adaptable, $r=0.24, p \leq 0.05$. There is still no evidence of the predictive role of Machiavellianism and sadism, or of the joint role of all the traits.

In the light of the recent evidence linking the dark personality to adaptive performance, we wish to investigate the potential value of incorporating the assessment of the Dark Tetrad over assessing only the classical Big Five personality traits.

\subsection{The Present Study}

There is a considerable amount of research linking personality to other performance dimensions. The present study aimed to investigate the role of personality in the prediction of adaptive performance. Specifically, we contribute to the previous literature in two ways: (1) by investigating the incremental validity of the Dark Triad over and above the Big Five; (2) by evaluating whether sadism (i.e., the Dark Tetrad) offers additional information in this context.

As stated above, previous studies have demonstrated the predictive value of four of the Big Five personality traits (neuroticism, extraversion, openness, and conscientiousness) for adaptive performance $[8,10,34]$. We expect to find the same relationship in our study. However, the role of agreeableness remains unresearched. As agreeableness is related to cooperativeness, helpfulness, and flexibility [41], and collaboration with others is common in adaptive situations at work, a positive relationship with adaptive performance is expected. Taking all of the aforementioned aspects into account, our first hypothesis is as follows:

Hypothesis 1. Big Five personality traits will be associated with adaptive performance.

Hypothesis 1 (H1a). Neuroticism will be negatively associated with adaptive performance.

Hypothesis 1 (H1b). Extraversion will be positively associated with adaptive performance.

Hypothesis 1 (H1c). Openness will be positively associated with adaptive performance.

Hypothesis 1 (H1d). Agreeableness will be positively associated with adaptive performance.

Hypothesis 1 (H1e). Conscientiousness will be positively associated with adaptive performance.

Previous research also has found support for the relationship between dark personality traits and adaptive performance. Specifically, psychopathy [22] and narcissism [23] were positively related to adaptive performance. Psychopaths could be more adaptive because they are charming, seductive, self-confident, composed, risk-seeking, and adept at impressing others, making it easier for them gain their colleagues' collaboration. Regarding narcissists, they tend to demonstrate their value to others, 
taking risks and behaving confidently [23]. Roczniewska and Bakker [42] found that narcissism was a positive predictor of seeking social resources, and that higher scores on this dark personality trait were associated with seeking challenges at work. This disposition to action is important in changing situations, whereas less adaptive people tend to maintain their behavior according to plan, even if the plans are not working.

Regarding the remaining dark traits, Machiavellians possess a higher impulse regulation [43], especially related to interpersonal control. They show a good ability to plan ahead, build strategic alliances, and try to maintain a positive reputation without thinking about others. Thus, is expected that Machiavellians will be able to manipulate their colleagues to reach their goals. Nevertheless, the case of sadism remains unclear. Sadistic individuals tend to show cruelty even without external stimulus [19] so this may makes it difficult for them to focus on behaving adaptively. Taking all the aforementioned into account, we propose the following hypothesis:

Hypothesis 2. Dark personality traits will be associated with adaptive performance.

Hypothesis 2 (H2a). Psychopathy will be positively associated with adaptive performance.

Hypothesis 2 (H2b). Narcissism will be positively associated with adaptive performance.

Hypothesis 2 (H2c). Machiavellianism will be positively associated with adaptive performance.

Hypothesis 2 (H2d). Sadism will be negatively associated with adaptive performance.

Several studies found that dark personality uniquely accounted for variance in the classical dimensions of job performance after controlling for the Big Five personality traits [40], but they did not examine what occurred with adaptive performance. As in other performance dimensions, it is expected that the Dark Triad would account for incremental variance in adaptive performance beyond the Big Five. This is our third hypothesis:

Hypothesis 3. The Dark Triad will increase the explained variance of adaptive performance above the Big Five.

We also outlined above the debate between Dark Triad and Dark Tetrad. To support the more complex model, sadism should demonstrate its incremental value over the Big Five and the Dark Triad. Given that sadism has unique characteristics different from narcissism, Machiavellianism, and psychopathy [19], the incorporation of this fourth trait in the predictive model of adaptive performance would also account for incremental variance with regard to the Big Five and the Dark Triad. Thus, our last hypothesis is as follows:

Hypothesis 4. Sadism will increase the explained variance of adaptive performance regarding the Big Five and the Dark Triad.

\section{Materials and Methods}

\subsection{Participants and Procedure}

The study was carried out in Spain. Six hundred and thirteen participants (46\% women), aged between 18 and 70 years $(M=38.78, S D=14.05)$, from different organizations $(72.8 \%$ private, $23.8 \%$ public, $3.4 \%$ NGOs) were involved in the study. They have an average of job experience of 16.93 years $(S D=13.39)$.

Our study uses a cross-sectional design. Although longitudinal designs are generally recommended, cross-sectional research is advisable in exploratory research such as this one, where the role of sadism and the incremental validity of the dark personality over the Big Five is still 
unclear [44]. Data were collected with non-probabilistic sampling. The first two authors requested their degree students to collaborate, distributing the questionnaire in pencil-and-paper format among workers they knew. Students received training in questionnaire completion to provide the necessary guidance to their recruits. Following the ethical standards in psychological research, participants were informed about the research objectives of this research and about the anonymity of their responses, accepting voluntarily to complete the questionnaire with all the variables of interest.

\subsection{Measures}

All measurements were recorded by self-report, a reliable and valid approach to assess dark personality [45], which is also appropriate in multi-occupational research where it may be difficult for others (i.e., supervisors, peers) to observe worker's performance [46].

\subsubsection{Control Variables}

We asked participants about their sex, age, and job experience because previous literature has shown that being a woman, young, and having job experience promotes adaptive performance $[10,31,33]$.

\subsubsection{Big Five Personality Traits}

Personality was assessed with the Spanish version of the NEO-FFI [47]. It consists of five 12-item dimensions rated on a 5-point Likert scale ranging from 1 (strongly disagree) to 5 (strongly agree). Cronbach's alpha values in our sample were: Neuroticism $=0.79$; Extraversion $=0.83$; Openness to experience $=0.73$; Agreeableness $=0.72$; and Conscientiousness $=0.78$.

\subsubsection{Dark Tetrad at Work}

The four traits that compose the Dark Tetrad were assessed with the Dark Tetrad at Work Scale [48] adapted to Spanish by Fernández-del-Río et al. [21]. It has 6 items for Narcissism, 4 for Machiavellianism, 6 for Psychopathy, and 6 for Sadism. The items were rated on a 5-point Likert scale ranging from 1 (strongly disagree) to 5 (strongly agree). Cronbach's alpha values in our sample were 0.61 for Narcissism, 0.75 for Machiavellianism, 0.78 for Psychopathy, and 0.91 for Sadism.

\subsubsection{Adaptive Performance}

Performance was assessed with the eight items of the Spanish version of the scale developed by Marques-Quinteiro, Ramos-Villagrasa, Passos, and Curral [5] and based on Pulakos and colleagues' taxonomy of adaptive behaviors [16]. The items are rated on a 7-point Likert scale ranging from 1 (totally ineffective) to 7 (totally effective). The observed Cronbach's alpha was 0.88 .

\subsection{Data Analysis}

Firstly, we computed the descriptive statistics of the variables (mean, standard deviation). Secondly, associations were assessed with Pearson correlations for numerical variables and with Cohen's $d$ for sex. Thirdly, predictive models of job performance were performed with hierarchical regression analysis with job experience in Step 1, Big Five in Step 2, Dark Triad in Step 3, and Sadism in Step 4. The analyses were performed with SPSS v.22.

\section{Results}

The descriptive statistics of the variables and their associations can be seen in Table 1. All the Big Five traits showed statistically significant correlations with each other $(\bar{r}=0.23$, range $=[0.04,0.40])$ except for Neuroticism with Openness to experience $(r=0.04, p=0.324)$ and Openness to experience with Agreeableness $(r=0.06, p=0.190)$. Neuroticism is the only factor that showed a negative association with the remaining Big Five: $r=-0.33, p<0.001$ with Extraversion, $r=-0.26, p<0.001$ with Agreeableness, and $r=-0.40, p<0.001$ with Conscientiousness. 
Table 1. Descriptive statistics and bivariate relations.

\begin{tabular}{|c|c|c|c|c|c|c|c|c|c|c|c|c|c|c|c|}
\hline Variable & $M$ & $S D$ & 1 & 2 & 3 & 4 & 5 & 6 & 7 & 8 & 9 & 10 & 11 & 12 & 13 \\
\hline 1. Sex & 1.54 & 0.50 & 1 & & & & & & & & & & & & \\
\hline 2. Age & 38.78 & 14.05 & $0.17 *$ & 1 & & & & & & & & & & & \\
\hline 3. Job experience & 16.93 & 13.39 & $-0.61^{* *}$ & $0.64^{* *}$ & 1 & & & & & & & & & & \\
\hline 4. Neuroticism & 31.07 & 7.08 & $-0.35^{* *}$ & $-0.15^{* *}$ & -0.08 & 1 & & & & & & & & & \\
\hline 5. Extraversion & 42.87 & 7.13 & -0.12 & $-0.19 * *$ & $-0.17^{* *}$ & $-0.33^{* *}$ & 1 & & & & & & & & \\
\hline 6. Openness & 38.59 & 6.23 & $-0.27^{* *}$ & $-0.14^{* *}$ & -0.08 & 0.04 & $0.25 * *$ & 1 & & & & & & & \\
\hline 7. Agreeableness & 41.66 & 6.12 & $-0.29 * *$ & $0.16^{* *}$ & $0.14^{* *}$ & $-0.26^{* *}$ & $0.25 * *$ & 0.06 & 1 & & & & & & \\
\hline 8. Conscientiousness & 44.91 & 6.00 & -0.01 & $0.09 *$ & 0.07 & $-0.40 * *$ & $0.32 * *$ & $0.12 * *$ & $0.28 * *$ & 1 & & & & & \\
\hline 9. Narcissism & 17.47 & 3.16 & $0.27^{* *}$ & $0.09 *$ & 0.07 & -0.07 & $0.18^{* *}$ & $0.11 * *$ & $-0.10 *$ & $0.14^{* *}$ & 1 & & & & \\
\hline 10. Machiavellianism & 10.84 & 3.30 & 0.06 & -0.06 & $-0.09 *$ & $0.33 * *$ & $-0.16^{* *}$ & $-0.10 *$ & $-0.32 * *$ & $-0.17^{* *}$ & 0.02 & 1 & & & \\
\hline 11. Psychopathy & 10.34 & 3.46 & $0.43 * *$ & -0.01 & 0.02 & $0.27^{* *}$ & $-0.21 * *$ & $-0.16^{* *}$ & $-0.33^{* *}$ & $-0.34 * *$ & $0.14^{* *}$ & $0.35^{* *}$ & 1 & & \\
\hline 12. Sadism & 8.20 & 3.44 & $0.23 * *$ & -0.03 & -0.01 & $0.21 * *$ & $-0.20^{* *}$ & $-0.09 *$ & $-0.30^{* *}$ & $-0.25^{* *}$ & $0.21 * *$ & $0.28 * *$ & $0.67^{* *}$ & 1 & \\
\hline $\begin{array}{l}\text { 13. Adaptive } \\
\text { performance }\end{array}$ & 41.40 & 7.18 & 0.11 & -0.01 & 0.01 & $-0.29 * *$ & $0.25 *$ & $0.21 * *$ & $0.13 * *$ & $0.30 * *$ & $0.16^{* *}$ & $-0.19^{* *}$ & $-0.24^{* *}$ & $-0.17^{* *}$ & 1 \\
\hline
\end{tabular}


Regarding the Dark Tetrad, excluding the relationship between Psychopathy and Sadism $(r=0.67$, $p<0.001)$, the remaining Dark Tetrad dimensions presented lower correlations with each other $(\bar{r}=0.20$, range $=[0.02,0.35])$. It is remarkable that Narcissism and Machiavellianism did not show a significant association $(r=0.02, p=0.576)$. As for its relationship with the Big Five, Narcissism had a positive relationship with Extraversion $(r=0.18, p<0.001)$ and Openness $(r=0.11, p=0.008)$, and a negative one with Agreeableness $(r=-0.10, p=0.011)$. Machiavellianism, Psychopathy and Sadism had a positive association with Neuroticism $(\bar{r}=0.27$, range $=[0.21,0.33])$ and negative ones with the rest of the Big Five $(\bar{r}=-0.22$, range $=[-0.34,-0.09])$.

All personality traits were related to Adaptive performance. Specifically, positive associations were found with Extraversion $(r=0.25, p<0.001)$, Openness $(r=0.21, p<0.001)$, Agreeableness $(r=0.13, p=0.002)$, Conscientiousness $(r=-0.30, p<0.001)$, and Narcissism $(r=0.16, p<0.001)$, and negative associations with Neuroticism $(r=-0.29, p<0.001)$, Machiavellianism $(r=-0.19$, $p<0.001)$, Psychopathy $(r=-0.24, p<0.001)$ and Sadism $(r=-0.17, p<0.001)$. Neither sex $(r=0.11$, $p=0.165)$ nor age $(r=-0.01, p=0.933)$ nor job experience $(r=0.01, p=0.804)$ showed an association with adaptive performance. None of the socio-demographic variables measured as controls were significantly related to adaptive performance.

Four-step regression analyses to predict adaptive performance were run (see Table 2). Step 1 included control variables, which did not contribute to explain adaptive performance $\left(R^{2}=\right.$ 0.003, $p=0.677$ ). Step 2 incorporated the Big Five personality traits, explaining $16.0 \%$ of the variance of adaptive performance $\left(\Delta R^{2}=0.159, p<0.001\right)$ and with Neuroticism $(\beta=-0.165, p$ $=0.001)$, Openness $(\beta=0.186, p<0.001)$ and Conscientiousness $(\beta=0.208, p<0.001)$ as statistically significant predictors. The inclusion of the Dark Triad (Step 3) to the models increased the explained variance of adaptive performance up to $20.2 \%\left(\Delta R^{2}=0.184, p<0.001\right)$, with Neuroticism $(\beta$ $=-0.127, p=0.010)$, Openness $(\beta=0.155, p<0.001)$, Conscientiousness $(\beta=0.164, p<0.001)$, $\operatorname{Narcissism}(\beta=0.134, p=0.002)$, and Psychopathy $(\beta=-0.147, p=0.005)$ as statistically significant predictors. The incorporation of Sadism (Step 4) did not increase the explained variance $\left(\Delta R^{2}=-0.001\right.$, $p=0.541)$. Thus, we considered Step 3 as the final one.

Table 2. Hierarchical regression analysis of adaptive performance.

\begin{tabular}{lcccccccc}
\hline & \multicolumn{2}{c}{ Step 1 } & \multicolumn{2}{c}{ Step 2 } & \multicolumn{2}{c}{ Step 3 } & \multicolumn{2}{c}{ Step 4 } \\
\hline & $R^{2}$ & 0.003 & $R^{2}$ & 0.172 & $R^{2}$ & 0.202 & $R^{2}$ & 0.202 \\
& Adjusted & & Adjusted & 0.159 & Adjusted & 0.184 & Adjusted & 0.183 \\
& $R^{2}$ & -0.003 & $R^{2}$ & $R^{2}$ & & \\
& $p$ & 0.667 & $p$ & $<0.001$ & $p$ & $<0.001$ & $p$ & 0.541 \\
\hline Variable & $\beta$ & $p$ & $\beta$ & $p$ & $\beta$ & $p$ & $\beta$ & $p$ \\
\hline Sex & -0.053 & 0.242 & -0.054 & 0.21 & -0.072 & 0.101 & -0.072 & 0.102 \\
Age & -0.024 & 0.686 & -0.013 & 0.815 & -0.025 & 0.65 & -0.027 & 0.628 \\
Job experience & -0.012 & 0.845 & 0.01 & 0.858 & 0.004 & 0.937 & 0.005 & 0.932 \\
Neuroticism & & & -0.165 & 0.001 & -0.127 & 0.01 & -0.127 & 0.011 \\
Extraversion & & & 0.07 & 0.152 & 0.042 & 0.385 & 0.038 & 0.443 \\
Openness & & & 0.186 & $<0.001$ & 0.155 & 0.001 & 0.155 & $<0.001$ \\
Agreeableness & & & -0.008 & 0.865 & -0.023 & 0.623 & -0.024 & 0.606 \\
Conscientiousness & & & 0.208 & $<0.001$ & 0.164 & 0.001 & 0.164 & 0.001 \\
Narcissism & & & & & 0.134 & 0.002 & 0.14 & 0.002 \\
Machiavellianism & & & & & -0.059 & 0.195 & -0.059 & 0.198 \\
Psychopathy & & & & & -0.137 & 0.005 & -0.118 & 0.044 \\
Sadism & & & & & & & -0.034 & 0.541 \\
\hline
\end{tabular}




\section{Discussion}

The purpose of the present research was to study the incremental value of dark personality traits over the Big Five in the prediction of adaptive performance. We began exploring the association between personality and adaptive performance. As expected, Neuroticism had a negative association with adaptive performance, and the remaining Big Five had a positive association, supporting Hypothesis 1. Regarding the dark traits, all of them had a negative association with adaptive performance, except for Narcissism, so we rejected Hypothesis 2. Regarding the predictive models, Hypothesis 3 was supported: the incorporation of the Dark Triad improved the incremental validity of adaptive performance over the Big Five. At the same time, Hypothesis 4 was not supported: Sadism did not improve the previous model, suggesting that the Dark Triad is sufficient to predict adaptive performance. The results of our study have some implications which will be discussed in the following paragraphs.

Firstly, the study provides further evidence that the Big Five predicts adaptive performance. As prior studies carried out with task, contextual, and counterproductive performance have demonstrated, the Big Five always plays an important role in the prediction of job performance, but the relevance of each personality trait varies according to the dimension under analysis. In accordance with this evidence, practitioners should have weighted the Big Five traits as a function of the specific performance dimensions of interest. In any event, Conscientiousness remains as the main trait to predict job performance. The results related to Openness to experience also merit some comments: previous studies with adaptive performance as criterion only found a relationship with adaptive performance measured at the team level [34], but it seems reasonable to think that people who like to explore new situations and opportunities are more receptive to adapting to situations also at the individual level. We believe that further research will verify this finding.

Secondly, it is also interesting that previous studies have suggested that Extraversion is an antecedent of adaptive performance [8,10]. In our data, this relationship disappeared when the dark traits were incorporated into the predictive model. We think that Narcissism may have buffered the impact of Extraversion on adaptive performance. Narcissists' characteristics [14], like lack of empathy or high propensity for engaging in exploitive behaviors, could moderate the positive effect of Extraversion on adaptive situations, whilst the overconfidence that also characterizes narcissists may help them to adapt.

Thirdly, two of the dark traits (i.e., Narcissism and Psychopathy) also showed their own predictive value, in accordance with previous research $[22,23]$. In our data, people with a high self-appraisal (i.e., high narcissism) and capable of being concerned about others (i.e., low psychopathy) found it easier to behave adaptively. The positive association between narcissism and adaptive performance is consistent with prior research $[23,42]$. This result may be explained in terms of beliefs about one's own skills, in the same way as the literature links self-efficacy and adaptive performance [10]. Regarding psychopathy, our results are opposed to those of Schütte et al.'s study [22]. However, their measure of adaptive performance focused only on dealing with changes and unexpected events, whereas ours had a wider spectrum, supported by Pulakos and colleagues' model [27]. Furthermore, the former authors only found a positive relationship when psychopathy was mediated by political skill. These differences may explain the discrepancies between the two studies. From our point of view, our results seem reasonable because psychopaths are also prone to impulsiveness and irresponsibility [49], which make it difficult behave adaptively in changing situations. In any event, the evidence is sufficient to draw conclusions, and further research may help to explain in which adaptive situations psychopaths may perform better. It is also important to note that Machiavellianism, the third trait of the Dark Triad, does not participate in the predictive model of adaptive performance, when it does so with other dimensions such as task and contextual performance [21,39]. This may be due to the excessive focus of Machiavellians on achieving their purposes, which does not facilitate the change that requires effective adaptation, but neither does it hinder it enough to contribute negatively, as is the case with psychopathy. In any case, this is only a tentative explanation, and future research should verify this hypothesis. 
Fourthly, our study demonstrates that the Dark Triad has incremental validity over the Big Five. This finding supports its usefulness in the prediction of adaptive performance. At the same time, this also contributes to the ongoing debate between the dimensionality of dark personality. Recent evidence points out that sadism plays a role over and above the Dark Triad in task performance, contextual performance, and counterproductive work behaviors [21] but this does not happen with adaptive performance. In our view, this result does not contradict the consideration of the Dark Tetrad against the Triad, but speaks in favor of considering adaptive performance as a dimension of performance in itself [28]. Therefore, it is expected that adaptive performance would exhibit its own relationships with personality traits, different from the ones that personality has with the remaining performance dimensions.

Fifthly, a strong correlation was found between psychopathy and sadism. This also has been found in other studies using different instruments [12], supporting the idea that they may be the same thing, or different facets of a broader construct. Authors like Plouffe and colleagues [50] have highlighted that this overlap could be due to the way in which sadism is measured (i.e., using items that reflect psychopathic features) when we should focus instead on assessing the sadist's essence, like the enjoyment of cruelty or the tendency to subjugation. Along with this, we must consider the fact that, contrary to our expectations, both psychopathy and sadism were negatively related to adaptive performance. This leads us to hypothesize that psychopathy needs the intervention of other variables, such as political skill [22], to have a positive effect on adaptation.

Like any study, our research has some limitations that should be pointed out. The most noteworthy is the use of self-reports to measure adaptive performance, because some participants may offer an excessively high self-appraisal. Nonetheless, these data come from a research context where all participants have a job, and the answers were anonymous. We believe that this situation reduces the risk of biased answers more than in a personnel selection process. In any event, it is also possible for narcissists to be so self-confident that they overrate their performance. We recommend that further research on the dark personality traits and adaptive performance use different measures to verify our results. Moreover, the use of a cross-sectional design precludes the establishment of causal relationships, but this type of design is acceptable when investigating new relationships, as in the present study [44]. Another limitation is related to the differences in the measures of the Big Five (i.e., composed of items referring to all situations) and the Dark Tetrad (i.e., specifically designed for the job context). We consider that it would be interesting to replicate this research with measures with the same level of specificity for the "bright" and "dark" traits to verify our results.

Continuing with ideas for further research, more research on the construct of adaptive performance itself is needed. To finally demonstrate that it should be incorporated as a fourth dimension of performance, we need empirical research that shows that adaptive performance contributes independently to overall job performance like the remaining dimensions, as has been done in the past with other dimensions. Another research proposal is related to the search for more predictors of adaptation among individual differences (e.g., biodata). In addition, we must consider that adaptive situations are diverse, requiring the display of different adaptive behaviors [27], which may imply that the role of personality traits varies according to the particularities of each adaptive episode [10]. Further research should analyze whether there is a differential role in the predictive capacity of personality traits depending on the adaptive behavior that is performed.

\section{Conclusions}

Summarizing our results, we can conclude that: (1) "bright" (i.e., Big Five) and "dark" (i.e., Dark Triad) personality play a role in predicting adaptive performance; (2) Conscientiousness continues to be the main personality trait to predict job performance; (3) Openness and Narcissism are the next most important predictors, right after Conscientiousness; and (4) high Neuroticism and Psychopathy make it harder to show adaptive behaviors at work. 
The present paper includes a question in its title: Does evil prevail? According to our data, we ought to say yes, but not for all "dark" profiles: narcissists, that is, over-confident people with a dysfunctional need to play the main character at the expense of coworkers, behave more adaptively than other profiles. Despite their potential for adaptive performance, narcissists also have other characteristics that may impact negatively on other organizational variables beyond performance (e.g., organizational climate), which should be considered to avoid toxic workplaces.

Author Contributions: Conceptualization, P.J.R.-V., E.F.-d.-R., and J.R.B.; methodology, J.R.B.; validation, P.J.R.-V.; formal analysis, P.J.R.-V.; investigation, P.J.R.-V. and E.F.d.R.; resources, P.J.R.-V. and E.F.R.; data curation, J.R.B.; writing—original draft preparation, P.J.R.-V.; writing—review and editing, P.J.R.-V., E.F.-d.-R., and J.R.B.; visualization, P.J.R.-V.; project administration, P.J.R.-V. All authors have read and agreed to the published version of the manuscript.

Funding: This research received no external funding.

Conflicts of Interest: The authors declare no conflict of interest.

\section{References}

1. Pfeffer, J. Building Sustainable Organizations: The Human Factor. Acad. Manag. Perspect. 2010, 24, 34-45.

2. Salgado, J.F.; Otero, I.; Moscoso, S. Cognitive Reflection and General Mental Ability as Predictors of Job Performance. Sustainability 2019, 11, 6498. [CrossRef]

3. Baard, S.K.; Rench, T.A.; Kozlowski, S.W.J. Performance Adaptation: A Theoretical Integration and Review. J. Manag. 2014, 40, 48-99. [CrossRef]

4. Brall, C.; Schröder-Bäck, P.; Porz, R.; Tahzib, F.; Brand, H. Ethics, health policy-making and the economic crisis: a qualitative interview study with European policy-makers. Int. J. Equity Health 2019, 18, 144. [CrossRef] [PubMed]

5. Mucci, N.; Giorgi, G.; Roncaioli, M.; Fiz Perez, J.; Arcangeli, G. The correlation between stress and economic crisis: a systematic review. NDT 2016, 983. [CrossRef] [PubMed]

6. Niessen, C.; Jimmieson, N.L. Threat of tesource loss: The role of self-regulation in adaptive task performance. J. Appl. Psychol. 2016, 101, 450-462. [CrossRef] [PubMed]

7. Mäder, I.A.; Niessen, C. Nonlinear associations between job insecurity and adaptive performance: The mediating role of negative affect and negative work reflection. Hum. Perform. 2017, 30, 231-253. [CrossRef]

8. Huang, J.L.; Ryan, A.; Zabel, K.L.; Palmer, A. Personality and adaptive performance at work: A meta-analytic investigation. J. Appl. Psychol. 2014, 99, 162-179. [CrossRef] [PubMed]

9. Marques-Quinteiro, P.; Vargas, R.; Eifler, N.; Curral, L. Employee adaptive performance and job satisfaction during organizational crisis: the role of self-leadership. Eur. J. Work Organ. Psychol. 2019, 28, 85-100. [CrossRef]

10. Jundt, D.K.; Shoss, M.K.; Huang, J.L. Individual adaptive performance in organizations: A review. J. Organ. Behav. 2015, 36, S53-S71. [CrossRef]

11. Barrick, M.R.; Mount, M.K. The Big Five Personality Dimensions and Job Performance: A Meta-Analysis. Pers. Psychol. 1991, 44, 1-26. [CrossRef]

12. Fernández del Río, E.; Ramos-Villagrasa, P.J.; Castro, Á.; Barrada, J.R. Sociosexuality and Bright and Dark Personality: The Prediction of Behavior, Attitude, and Desire to Engage in Casual Sex. Int. J. Environ. Res. Public Health 2019, 16, 2731. [CrossRef] [PubMed]

13. Koehn, M.A.; Jonason, P.K.; Davis, M.D. A person-centered view of prejudice: The Big Five, Dark Triad, and prejudice. Personal. Individ. Differ. 2019, 139, 313-316. [CrossRef]

14. Paulhus, D.L.; Williams, K.M. The Dark Triad of personality: Narcissism, Machiavellianism, and psychopathy. J. Res. Personal. 2002, 36, 556-563. [CrossRef]

15. Myung, J.K.; Choi, Y.H.; Kim, J.D. Effects of CEOs' Negative Traits on Corporate Social Responsibility. Sustainability 2017, 9, 543. [CrossRef]

16. Schimmenti, A.; Jonason, P.K.; Passanisi, A.; La Marca, L.; Di Dio, N.; Gervasi, A.M. Exploring the Dark Side of Personality: Emotional Awareness, Empathy, and the Dark Triad Traits in an Italian Sample. Curr. Psychol. 2019, 38, 100-109. [CrossRef] 
17. Smith, S.F.; Lilienfeld, S.O. Psychopathy in the workplace: The knowns and unknowns. Aggress. Violent Behav. 2013, 18, 204-218. [CrossRef]

18. Paulhus, D.L. Toward a Taxonomy of Dark Personalities. Curr. Dir. Psychol. Sci. 2014, 23, 421-426. [CrossRef]

19. Buckels, E.E.; Jones, D.N.; Paulhus, D.L. Behavioral Confirmation of Everyday Sadism. Psychol. Sci. 2013, 24, 2201-2209. [CrossRef]

20. Međedović, J.; Petrović, B. The Dark Tetrad: Structural properties and location in the personality space. J. Individ. Differ. 2015, 36, 228-236. [CrossRef]

21. Fernández-del-Río, E.; Ramos-Villagrasa, P.J.; Barrada, J.R. Bad guys perform better? The incremental predictive validity of the Dark Tetrad over Big Five and Honesty-Humility. Personal. Individ. Differ. 2020, 109700. [CrossRef]

22. Schütte, N.; Blickle, G.; Frieder, R.; Schnitzler, F.; Heupel, J. Political skill moderates the success of psychopaths at the workplace. In Proceedings of the 75th Annual Conference of the Academy of Management, Vancouver, BC, Canada, 7-11 August 2015.

23. Smith, M.B.; Webster, B.D. Narcissus the innovator? The relationship between grandiose narcissism, innovation, and adaptability. Personal. Individ. Differ. 2018, 121, 67-73. [CrossRef]

24. Rotundo, M.; Sackett, P.R. The relative importance of task, citizenship, and counterproductive performance to global ratings of job performance: A policy-capturing approach. J. Appl. Psychol. 2002, 87, 66-80. [CrossRef] [PubMed]

25. Burke, M.J.; Sarpy, S.A.; Tesluk, P.E.; Smith-Crowe, K. General Safety Performance: A Test of a Grounded Theoretical Model. Pers. Psychol. 2002, 55, 429-457. [CrossRef]

26. Janssen, O. Job demands, perceptions of effort-reward fairness and innovative work behaviour. J. Occup. Organ. Psychol. 2000, 73, 287-302. [CrossRef]

27. Pulakos, E.D.; Arad, S.; Donovan, M.A.; Plamondon, K.E. Adaptability in the workplace: Development of a taxonomy of adaptive performance. J. Appl. Psychol. 2000, 85, 612-624. [CrossRef]

28. Dorsey, D.W.; Cortina, J.M.; Waters, S.D.; Green, J.P.; Luchman, J. Adaptive and citizenship-related behaviors at work. In Handbook of Employee Selection, 2nd ed.; Farr, J.L., Tippins, N.T., Eds.; Routledge: New York, NY, USA, 2017; pp. 448-475.

29. Griffin, M.A.; Parker, S.K.; Mason, C.M. Leader vision and the development of adaptive and proactive performance: A longitudinal study. J. Appl. Psychol. 2010, 95, 174-182. [CrossRef]

30. Fernández del Río, E.; Barrada, J.R.; Ramos-Villagrasa, P.J. Bad Behaviors at Work: Spanish Adaptation of the Workplace Deviance Scale. Curr. Psychol. 2018. [CrossRef]

31. Pulakos, E.; Dorsey, D.; White, S. Adaptability in the Workplace: Selecting an Adaptive Workforce. In Advances in Human Performance and Cognitive Engineering Research; Shawn Burke, C., Pierce, L., Salas, E., Eds.; Elsevier: Amsterdam, The Netherlands, 2006; Volume 6, pp. 41-71.

32. Marques-Quinteiro, P.; Ramos-Villagrasa, P.J.; Passos, A.M.; Curral, L. Measuring adaptive performance in individuals and teams. Team Perform. Manag. 2015, 21, 339-360. [CrossRef]

33. Pulakos, E.D.; Schmitt, N.; Dorsey, D.W.; Arad, S.; Borman, W.C.; Hedge, J.W. Predicting Adaptive Performance: Further Tests of a Model of Adaptability. Hum. Perform. 2002, 15, 299-323. [CrossRef]

34. Christian, J.S.; Christian, M.S.; Pearsall, M.J.; Long, E.C. Team adaptation in context: An integrated conceptual model and meta-analytic review. Organ. Behav. Hum. Decis. Process. 2017, 140, 62-89. [CrossRef]

35. Lee, K.; Ashton, M.C. Psychopathy, Machiavellianism, and Narcissism in the Five-Factor Model and the HEXACO model of personality structure. Personal. Individ. Differ. 2005, 38, 1571-1582. [CrossRef]

36. Lee, K.; Ashton, M.C. The Dark Triad, the Big Five, and the HEXACO model. Personal. Individ. Differ. 2014, 67, 2-5. [CrossRef]

37. Book, A.; Visser, B.A.; Blais, J.; Hosker-Field, A.; Methot-Jones, T.; Gauthier, N.Y.; Volk, A.; Holden, R.R.; D'Agata, M.T. Unpacking more "evil": What is at the core of the dark tetrad? Personal. Individ. Differ. 2016, 90, 269-272. [CrossRef]

38. Hodson, G.; Book, A.; Visser, B.A.; Volk, A.A.; Ashton, M.C.; Lee, K. Is the Dark Triad common factor distinct from low Honesty-Humility? J. Res. Personal. 2018, 73, 123-129. [CrossRef]

39. O’Boyle, E.H.; Forsyth, D.R.; Banks, G.C.; McDaniel, M.A. A meta-analysis of the Dark Triad and work behavior: A social exchange perspective. J. Appl. Psychol. 2012, 97, 557-579. [CrossRef] [PubMed]

40. Grijalva, E.; Harms, P.D.; Newman, D.A.; Gaddis, B.H.; Fraley, R.C. Narcissism and Leadership: A Meta-Analytic Review of Linear and Nonlinear Relationships. Pers. Psychol. 2015, 68, 1-47. [CrossRef] 
41. Digman, J.M. Personality Structure: Emergence of the Five-Factor Model. Annu. Rev. Psychol. 1990, 41, 417-440. [CrossRef]

42. Roczniewska, M.; Bakker, A.B. Who Seeks Job Resources, and Who Avoids Job Demands? The Link Between Dark Personality Traits and Job Crafting. J. Psychol. 2016, 150, 1026-1045. [CrossRef]

43. Jones, D.N.; Paulhus, D.L. Machiavellianism. In Handbook of Individual Differences in Social Behavior; Leary, M.R., Hoyle, R.H., Eds.; Guildford: New York, NY, USA, 2009; pp. 93-108.

44. Spector, P.E. Do Not Cross Me: Optimizing the Use of Cross-Sectional Designs. J. Bus. Psychol. 2019, 34, 125-137. [CrossRef]

45. Jones, D.N.; Paulhus, D.L. Introducing the Short Dark Triad (SD3): A Brief Measure of Dark Personality Traits. Assessment 2014, 21, 28-41. [CrossRef] [PubMed]

46. Ramos-Villagrasa, P.J.; Barrada, J.R.; Fernández-del-Río, E.; Koopmans, L. Assessing Job Performance Using Brief Self-report Scales: The Case of the Individual Work Performance Questionnaire. Rev. Psicol. Trab. Organ. 2019, 35, 195-205. [CrossRef]

47. Costa, P.; McCrae, R.R. Inventario de Personalidad NEO Revisado (NEO PI-R). Inventario NEO reducido de Cinco factores (NEO- FFI) [Revised NEO Personality Inventory - NEO PI-R]; TEA: Madrid, Spain, 2008.

48. Thibault, T. The Dark Tetrad at Work; Saint Mary's University: Halifax, NS, Canada, 2016.

49. Neumann, C.S.; Hare, R.D. Psychopathic traits in a large community sample: Links to violence, alcohol use, and intelligence. J. Consult. Clin. Psychol. 2008, 76, 893-899. [CrossRef] [PubMed]

50. Plouffe, R.A.; Smith, M.M.; Saklofske, D.H. A psychometric investigation of the Assessment of Sadistic Personality. Personal. Individ. Differ. 2019, 140, 57-60. [CrossRef]

(C) 2020 by the authors. Licensee MDPI, Basel, Switzerland. This article is an open access article distributed under the terms and conditions of the Creative Commons Attribution (CC BY) license (http://creativecommons.org/licenses/by/4.0/). 